\title{
Proliferative activity and apoptosis of Langerhans histiocytes in eosinophilic granulomas as evaluated by MIB-1 and TUNEL methods
}

\author{
Y Hamada, T Iwaki, M Fukui, J Tateishi
}

\begin{abstract}
Aims-To identify the role played by apoptosis in tumour regression.

Methods-The growth fraction and apoptotic cell loss of four cases of eosinophilic granuloma were investigated using monoclonal antibodies against $\mathrm{Ki}-67$ proliferation marker (MIB-1) antigen and the TdT mediated dUTP-biotin $3^{\prime}$-OH nick end labelling (TUNEL) method. These data were then compared with the clinical growth rate.
\end{abstract}

Results-Only the Langerhans histiocytic cells, which reacted positively with antiS-100 protein antibody, were immunolabelled with antibodies to proliferating cell nuclear antigen and $\mathrm{Ki}-67$ antigen (MIB-1). Many apoptotic figures of histiocytic cells were also detected in all cases by the TUNEL method. In a patient whose tumour clinically showed spontaneous regression, the TUNEL staining index gave a higher score than the MIB-1 staining index.

Conclusions-The main cause of the spontaneous regression of the tumours was postulated to be programmed cell death (apoptosis).

(f Clin Pathol: Mol Pathol 1995;48:M251-M255)

Keywords: Eosinophilic granuloma, Langerhans cell histiocytosis, apoptosis, MIB-1, TUNEL method, cell kinetics.

Cell kinetics studies are thought to be useful in gaining a better understanding of the nature of tumour cells. The subpopulation of proliferating cells can be identified by using bromodeoxyuridine labelling and MIB-1 immunostaining. ${ }^{1}$ Tumours such as eosinophilic granuloma, infantile myofibromatosis, rhabdomyoma, and malignant lymphoma often shown spontaneous regression after rapid growth. Such regression is considered to be secondary to apoptosis. ${ }^{23}$ Eosinophilic granuloma is a benign disease of the bone which is most commonly located in the skull and is characterised by infiltration with both Langerhans histiocytes and eosinophils. ${ }^{4}$ Eosinophilic granuloma has recently been classified as one of the benign forms of Langerhans cell histiocytosis. ${ }^{56}$ Sometimes, these tumours show spontaneous regression. In order to identify the role that apoptosis plays in this regression, we studied four cases of eosinophilic granuloma by using the TdT mediated dUTP-biotin $3^{\prime}-\mathrm{OH}$ nick end labelling (TUNEL) method. ${ }^{7}$ DNA fragmentation can be found in cells undergoing apoptosis, and $\mathrm{TdT}$ is used to incorporate biotinylated dUTP at sites of DNA breaks. Since DNA fragmentation can be found not only in the histologically defined apoptotic cells but also in the morphologically intact cells, the extent of apoptosis revealed by the TUNEL method is greater than apoptosis detected by morphology. ${ }^{78}$ Our study shows that Langerhans cells in eosinophilic granulomas die through an apoptotic process. This may eventually result in spontaneous regression.

\section{Case reports}

Tumour specimens of eosinophilic granulomas in the skull were obtained at surgery in the department of neurosurgery, Kyushu University Hospital.

\section{CASE 1}

The patient was a 1 year old Japanese boy. A mass in the right retroauricular region was noticed by his parents in 1993. It grew rapidly from 1 to $7 \mathrm{~cm}$ in diameter within three months. A discrete area was revealed in the right retroauricular region by a skull $x$ ray examination (fig 1A). The tumour was totally removed without any preoperative radiotherapy or chemotherapy. The bony defect of the skull was $4 \mathrm{~cm}$ in diameter, and the tumour was loosely attached to the dura mater, from which it could easily be dissected. After the operation, another mass in the right ethmoid sinus developed. $\mathrm{He}$ was transferred to the department of paediatrics, Kyushu University Hospital, and was treated with chemotherapeutic agents including ethoposide, prednisolone, and vinblastin. In addition, radiotherapy at a dose of $6 \mathrm{~Gy}$ was given to the right temporal region and ethmoidal region. There has since been no evidence of recurrence over a period of 10 months.

\section{CASE 2}

The patient was a 9 year old Japanese girl. She noticed a mass and pain in the left frontal region in 1992. It grew from 1 to $4 \mathrm{~cm}$ in diameter within two months. A discrete area \\ Feurological Institute, \\ Maidashi 3-1-1, \\ 1 June 1995 \\ Department of
}



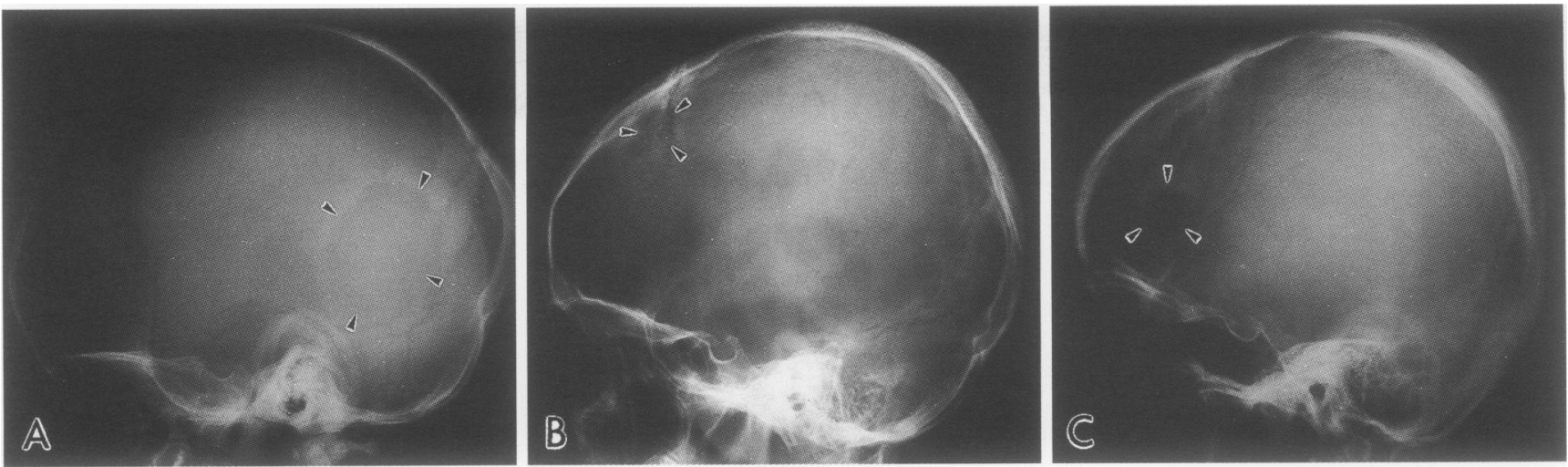

Figure 1 Lateral views of skull $x$ ray examination: $(A)$ case 1: a large discrete area in the retroauricular region (arrowheads); (B) case 2: a discrete area in the frontal region (arrowheads); (C) case 3: a discrete area in the frontal region (arrowheads).

was revealed in the left frontal region by a skull $x$ ray examination (fig $1 \mathrm{~B}$ ). The tumour was totally removed without any preoperative radiotherapy or chemotherapy. The bony defect of the skull was $1.5 \mathrm{~cm}$ in diameter. The mass could easily be dissected from the dura mater. After the operation, she was transferred to the department of paediatrics, Kyushu University Hospital, and radiotherapy at a dose of 6 Gy was given to the whole brain. There has since been no evidence of recurrence over two years.

CASE 3

The patient was a 22 year old Japanese woman. She noticed a mass and pain in the right frontal region in 1984 . It grew from 1 to $2.5 \mathrm{~cm}$ in diameter within three months. A discrete area was revealed in the right frontal region by a skull $x$ ray examination (fig $1 \mathrm{C}$ ). The tumour was totally removed, and no additional treatment was given. There has since been no evidence of recurrence over 10 years.

\section{CASE 4}

The patient was an 8 year old Japanese boy. $\mathrm{He}$ developed convulsions in 1987 and a mass was observed in the frontal lobe with a frontal bone defect by computerised tomography. The diameter of the mass decreased from $8 \mathrm{~mm}$ to $4.5 \mathrm{~mm}$ during two weeks. The tumour was totally removed, and no additional treatment was given. There has since been no evidence of recurrence over seven years.

\section{Methods}

Formalin fixed, paraffin embedded biopsied specimens of four eosinophilic granulomas in the skull were examined. The sections were routinely stained with haematoxylin and eosin.

Immunohistochemical staining was performed using a biotin-streptavidin peroxidase technique. Briefly, $5 \mu \mathrm{m}$ thick sections were deparaffinised in xylene and dehydrated in graded ethanol. After rinsing with tap water, the sections were completely immersed into $0.01 \mathrm{M}$ citrate buffer, $\mathrm{pH} 6.0$, and were boiled for $20 \mathrm{~min}$ or autoclaved for $10 \mathrm{~min}$ to enhance the immunoreactivity. After pretreatment, the sections were washed again with tap water and then with Tris- $\mathrm{HCl}$ buffer $(50 \mathrm{mM}$ Tris, $\mathrm{pH}$ $7 \cdot 6$ ) for $5 \mathrm{~min}$, and incubated with $0.3 \% \mathrm{H}_{2} \mathrm{O}_{2}$ in absolute methanol for $30 \mathrm{~min}$. Next, the sections were washed with Tris- $\mathrm{HCl}$ buffer three times, and incubated with primary antibody in 5\% non-fat milk with TBST ( $25 \mathrm{mM}$ Tris, $0.5 \mathrm{M} \mathrm{NaCl}, 0.05 \%$ Tween $20,0.05 \%$ $\mathrm{NaN}_{3}$ ) overnight at $4^{\circ} \mathrm{C}$. In addition, the sections were also washed with Tris- $\mathrm{HCl}$ buffer three times and incubated with biotinylated secondary antibodies in 5\% non-fat milk with TBST for $60 \mathrm{~min}$. After rinsing, the sections were incubated with horseradish peroxidase conjugated streptavidin for $30 \mathrm{~min}$. The coloured reaction products were developed in $0.02 \%$ diaminobenzidine in $50 \mathrm{mM}$ Tris- $\mathrm{HCl}$ buffer containing $0.003 \% \mathrm{H}_{2} \mathrm{O}_{2}\left(\mathrm{DAB} / \mathrm{H}_{2} \mathrm{O}_{2}\right.$ solution) for 5-15 min. The sections were lightly counterstained with haematoxylin.

The primary antibodies used were: (1) polyclonal anti-bovine S-100 protein antibody (DAKOPATTS, Denmark, diluted 1:500); (2) monoclonal anti-human $\mathrm{Ki}-67$ antigen antibody MIB-1 (Immunotek, France, diluted 1: 100); and (3) monoclonal anti-human PCNA antibody PC-10 (Novocastra Laboratories, UK, diluted $1: 100$ ).

The detection of DNA degradation in situ by the TUNEL method was done as follows. DNA fragmentation in situ associated with apoptosis was detected by nick end labelling according to the method of Gavrieli et al. ${ }^{7}$ Briefly, formalin fixed, paraffin embedded sections were deparaffinised, washed with distilled water, and treated with proteinase $\mathrm{K}(20 \mu \mathrm{g} / \mathrm{ml})$ in $100 \mathrm{mM} \mathrm{NaCl}, 10 \mathrm{mM}$ Tris- $\mathrm{HCl}, 25 \mathrm{mM}$ EDTA, $0.05 \%$ SDS (sodium dodecyl sulphate), at room temperature for $15 \mathrm{~min}$. Then the sections were washed with distilled water and incubated with $2 \% \mathrm{H}_{2} \mathrm{O}_{2}$ solution for 5 min to eliminate any endogenous peroxidase. Each section was then washed with distilled water and treated with $\mathrm{TdT}$ buffer solution ( $140 \mathrm{mM}$ sodium cacodylate, $30 \mathrm{mM}$ Tris$\mathrm{HCl}, 1 \mathrm{mM}$ cobalt chloride) containing TdT (terminal deoxynucleotidyl transferase, 0.3 equivalent $U / \mu \mathrm{l}, \mathrm{Gibco}$ ) and $0.1 \mathrm{mM}$ biotinylated dUTP (Boehringer Mannheim). The sections were gently covered by glass coverslips and incubated at $37^{\circ} \mathrm{C}$ for $90 \mathrm{~min}$ in a hu- 

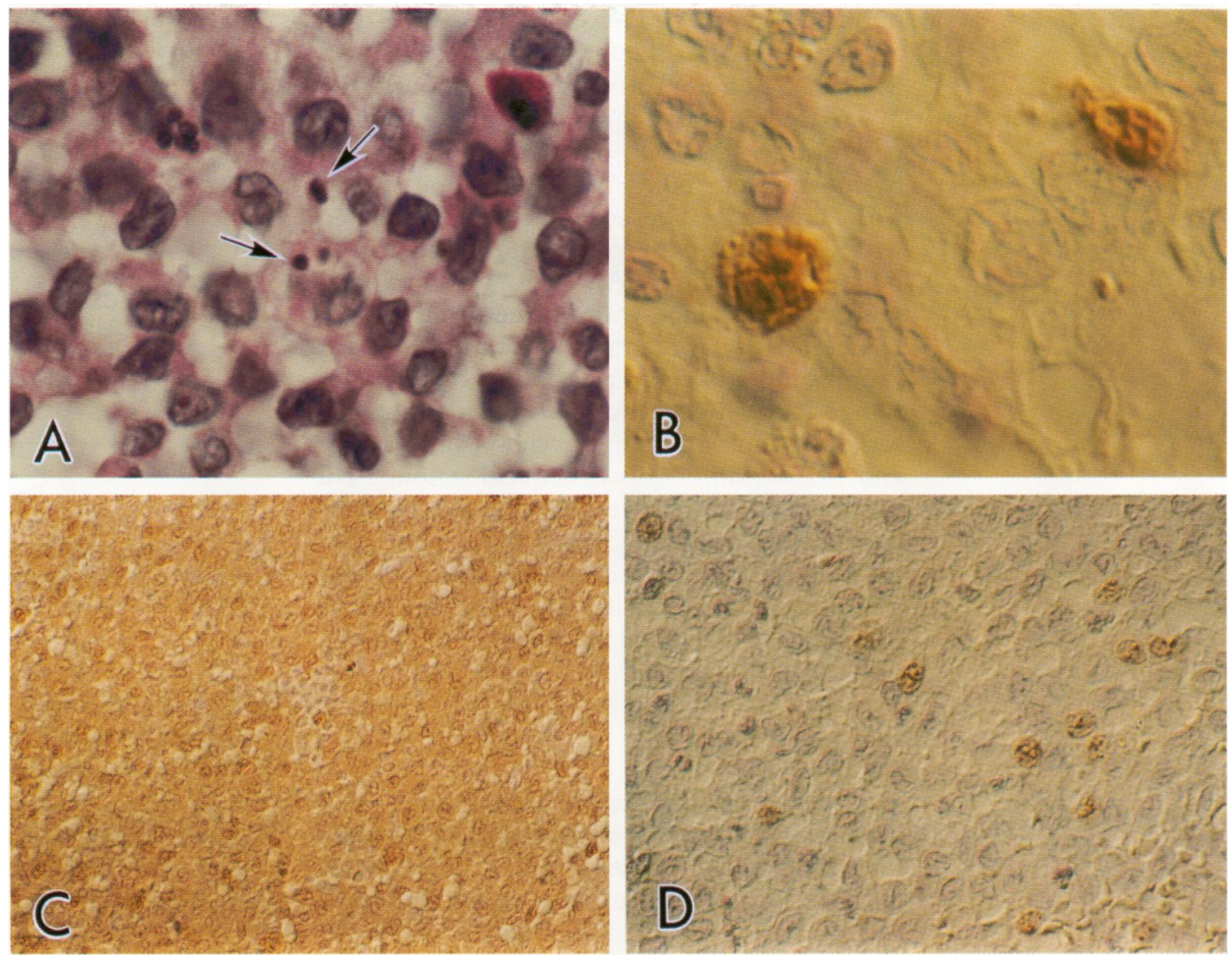

Figure 2 Histological appearance of eosinophilic granuloma of the skull (case 1), showing some apoptotic bodies (arrows) in haematoxylin-eosin staining $(A) \times 1000$; positive findings with the TUNEL method $(B) \times 2000$; diffusely positive with S-100 immunohistochemical staining $(C) \times 250$; and many positive cells with MIB-1 immunohistochemical staining $(D) \times 500$.
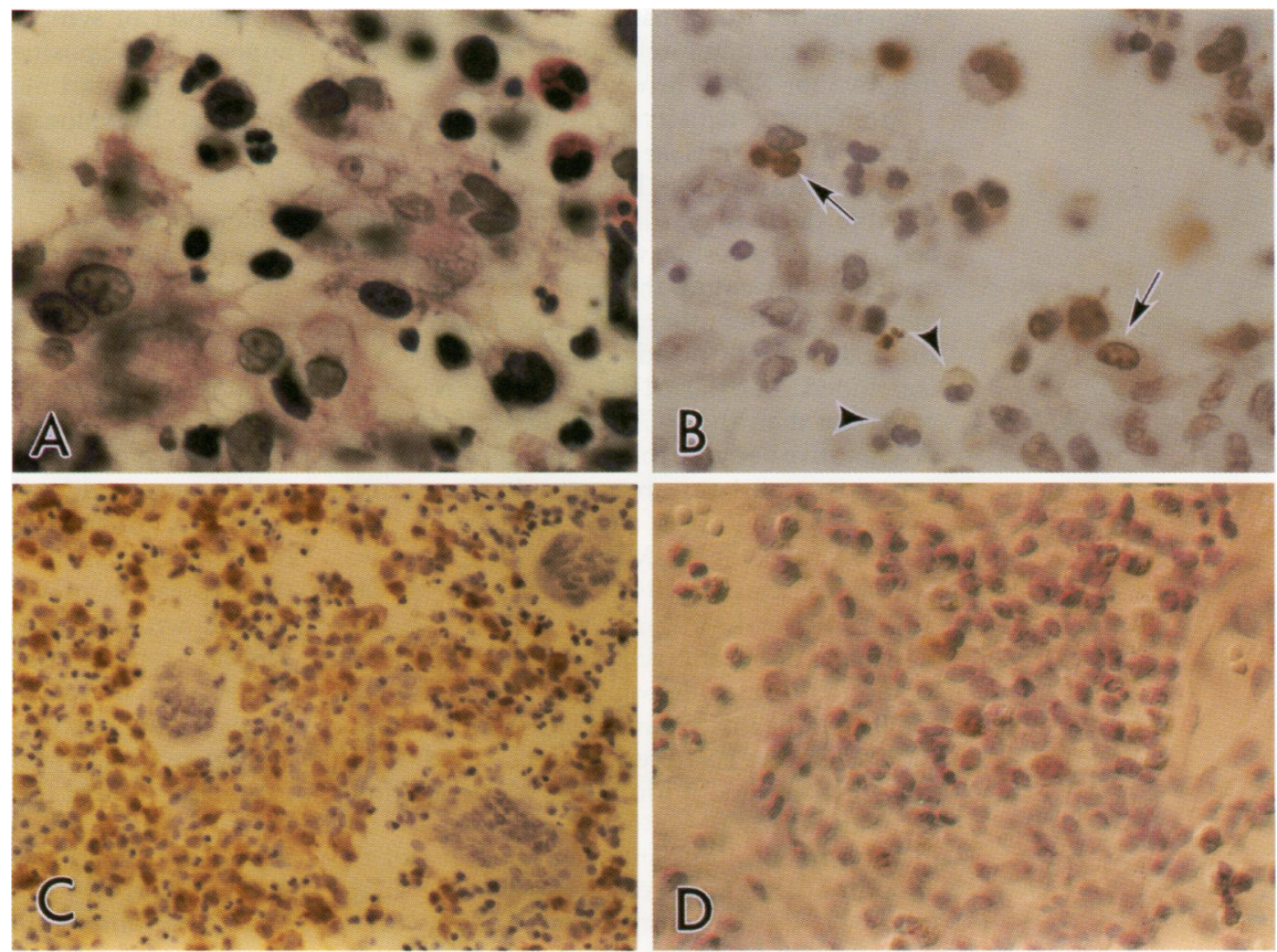

Figure 3 Histological appearance of eosinophilic granuloma of skull (case 4), showing many apoptotic bodies in haematoxylin-eosin staining $(A) \times 1000$, and many positive findings with the TUNEL method $(B) \times 400$. Apoptotic bodies and some Langerhans histiocytes were positive (arrows), while the eosinophils were negative (arrowheads). Positive cells with S-100 immunohistochemical staining were seen focally and foreign body giant cells were negative (C) $\times 250$. A few positive cells with MIB-1 immunohistochemical staining are seen in (D) $\times 500$. 
midified chamber. The coverslips were then removed and the sections were washed with $2 \times$ SSC buffer ( $30 \mathrm{mM}$ sodium citrate, $300 \mathrm{mM}$ chloride) for $15 \mathrm{~min}$ at room temperature, washed with distilled water, covered by $5 \%$ non-fat milk with TBST, and washed with Tris- $\mathrm{HCl}$. The sections were incubated with peroxidase conjugated streptavidin for 30 min, stained with $\mathrm{DAB} / \mathrm{H}_{2} \mathrm{O}_{2}$ solution, and then counterstained with haematoxylin.

The MIB-1 staining index and TUNEL staining index were both determined as follows: Langerhands histiocytic cells were identified by serial sections of haematoxylin-eosin staining and S-100 immunohistochemical staining. All positive cells of MIB-1 and TUNEL staining were considered to be histiocytic cells. The positive cells in each case were counted and the ratio of positive cells per 1000 Langerhans histiocytic cells was calculated according to the method of Ohta et al. ${ }^{9}$

\section{Results}

The four cases consisted histologically of a nodular proliferation of histiocytic cells with focal infiltration by some lymphocytes and eosinophils. Mitotic figures were scattered in case 1 and rarely seen in cases 2 and 3 . Since the specimen of case 3 showed rich connective tissue and remarkable lymphocytic infiltration, the tumour was considered to be a chronic stage of eosinophilic granuloma. Foreign body giant cells were seen often in case 4 but rarely in cases 2 and 3 . The main component cells with either folded or indented nuclei were strongly positive for S-100 protein (fig $2 \mathrm{C}$, fig $3 \mathrm{C})$. On the other hand, all other cell components including foreign body giant cells were negative for S-100 protein (fig 3C).

Proliferative activity was evaluated by proliferating cell nuclear antigen (PCNA) and MIB-1. However, the PCNA study resulted in variable degrees of staining of the histiocytic cells, and as a result, we could not accurately evaluate and count the positive cells by this method. On the other hand, the MIB-1 study showed distinctly positive staining, and we thus concluded that the MIB-1 index is more appropriate than the PCNA index in evaluating proliferative activity. In cases 1 and 2, the MIB1 positive cells were recognised often, but in case 3 positive cells were rarely seen. The staining index for the MIB-1 in histiocytes was as follows: case $1,10 \cdot 1 \%$; case $2,6 \cdot 7 \%$; case $3,0 \cdot 8 \%$; case $4,3 \cdot 9 \%$.

Typical apoptotic cells generally have small pyknotic nuclei and eosinophilic hyalinised cytoplasm in haematoxylin-eosin staining. Apoptotic cells were scattered in cases 1 and 4 , and phagocytosed apoptotic bodies were sometimes recognised (fig $2 \mathrm{~A}$, fig $3 \mathrm{~A}$ ). However, this method is not sufficient for evaluating all the apoptotic cells correctly because some apoptotic cells do not always show small pyknotic nuclei. In the early stages of apoptosis before morphological changes, the DNA breaks are recognised within the nucleus. ${ }^{1011} \mathrm{We}$ therefore used the TUNEL method to identify DNA fragmentation and its relation to apoptosis. ${ }^{7}$ In

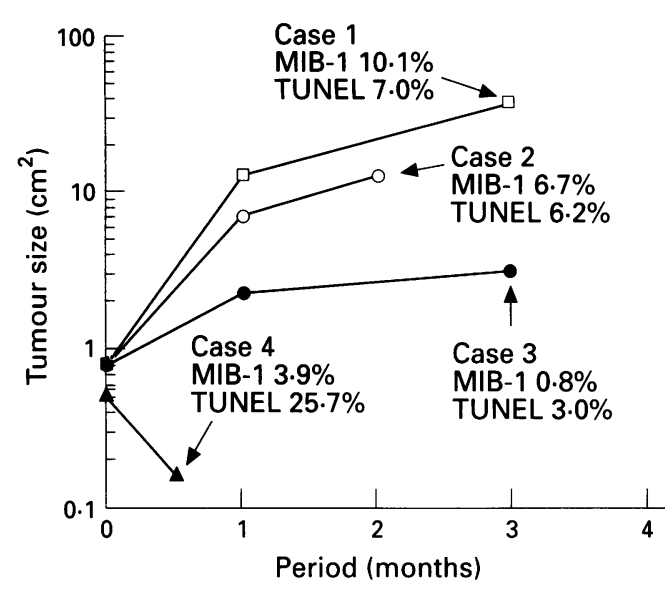

Figure 4 Growth curves of the tumour areas in the four cases presented. The percentages of MIB-1 and TUNEL staining indices are indicated.

cases 1 and 2, posiive cells were distributed in a scattered fashion. The staining index of the TUNEL method was as follows: case $1,7 \cdot 0 \%$; case $2,6 \cdot 2 \%$; case $3,3.0 \%$; case $4,25 \cdot 7 \%$. The tumour of case 1 clinically showed rapid growth, and histologically revealed both proliferative activity and apoptosis. On the other hand, the tumour of case 3 clinically showed indolent growth, and histologically showed rich connective tissue and moderate numbers of apoptotic figures. In case 4 , the tumour clinically showed spontaneous regression, and histologically revaled a large amount of apoptosis. In addition, we investigated the relation between tumour size, which was calculated on the basis of the tumour diameter and the period after onset of symptoms (fig 4). Tumour size appeared to be positively correlated with a high MIB-1 index and negatively correlated with a low TUNEL value.

\section{Discussion}

Eosinophilic granuloma is generally a benign tumour of the bone characterised by infiltrates of mononuclear histiocytes and eosinophils. It has become evident that eosinophilic granuloma is actually a proliferative disease of Langerhans cells. The new term of "Langerhans cell histiocytosis (LCH)" has now become widely accepted. ${ }^{612}$ The Langerhans cell is a dendritic, antigen presenting cell characterised by intracytoplasmic Birbeck granules and by the expression of CD1a glycoprotein..$^{513}$ It is well known that Langerhans cells show positive immunostaining for S-100 protein. We observed that all histiocytic cells in the tumours were immunopositive for S-100 protein. Those cells were focally positive for PCNA and more generally positive for MIB-1. There appeared to be a positive correlation between tumour size and MIB-1 staining. In addition, eosinophilic granuloma is well known to be a spontaneously regressing tumour, although there has been no documentation of the exact mechanism of this spontaneous regression.

We investigated the histology of each case while paying special reference to the growth of the tumour (fig 4). Case 1 showed a remarkable 
tumour growth activity, corresponding to a high score on the MIB-1 staining index. Case 3 clinically showed indolent tumour growth, and histologically showed a low score on the MIB1 staining index. Case 4 clinically showed spontaneous regression, which corresponded to a high TUNEL score. Case 2 showed a moderate score of both the MIB-1 staining index and the TUNEL score. The tumour in case 2 had a clinical corse that was intermediate between the tumours of cases 1 and 3 and also had an intermediate MIB-1 and TUNEL score (fig 4). Eosinophilic granulomas are generally classified as having two stages, the stage of cell infiltration and the stage of fibrosis. ${ }^{14}$ Cases 1 and 2 were at the stage of cell infiltration, while case 3 was at the stage of fibrosis. On the other hand, case 4 was in the so called regressive stage, in which apoptosis was dominant compared to proliferation. We could show that tumour size in the stage of cell infiltration corresponded to the MIB- 1 index and tumour size in the regressive stage corresponded to the TUNEL score (fig 4).

Since the volume of a tumour is controlled by the balance of proliferative cells and apoptotic cells, ${ }^{1516}$ the tumour is considered to shrink when the latter predominates over the former. Reed also reported a simple balanced equation in which the "rate of cell death" subtracted from the "rate of cell proliferation" leaves the "rate of cell accumulation". ${ }^{17}$ Based on our findings, we also postulated that the spontaneous regression in the eosinophilic granuloma is triggered by tumour cell apoptosis. The aetiology and pathogenesis of Langerhans cell histiocytosis remains unclear. The disorder is thought to be a manifestation of an immunological aberration, and in recent studies it has been considered to represent a clonal proliferation of histiocytes, which are characteristic of neoplasia. ${ }^{1318}$ Langerhans cell histiocytosis may be suitable for examining tumour cell kinetics, because it can show both rapid growth and spontaneous regression.

Langerhans cell histiocytosis consists of proliferative histiocytic cells, and its spontaneous regression must thus be due to apoptosis. Since this tumour is accompanied by a variety of inflammatory cell components, and a local injection of glucocorticoid often reduced its size, all humoral factors, such as tumour necrosis factor, which may trigger the apoptotic programme therefore need to be investigated. ${ }^{19-21}$

1 Shibuya M, Ito S, Miwa T, Davis RL, Wilson CB, Hoshino T. Proliferative potential of brain tumours: analyses with $\mathrm{Ki}-67$ and anti-DNA polymerase alpha monoclonal anibodies, bromodeoxyuridine labeling, and nucleolar organizer region counts. Cancer 1993;71:199-206.

2 Fukasawa Y, Ishikura H, Takada A, Yokoyama S, Imamura $\mathrm{M}$, Yoshiki $\mathrm{T}$, et al. Massive apoptosis in infantile myofibromatosis, putative mechanism of tumor regression. Am $\mathcal{F}$ Pathol 1994;144:480-5.

3 Leoncini L, Del Vecchio MT, Megha T, Barbini P, Galient $\mathrm{P}$, Pileri S, et al. Correlations between apoptotic and proliferative indices in malignant non-Hodgkin's lymphomas. Am f Pathol 1993;142:755-63.

4 Rawlings CE, Wilkins RH. Solitary eosinophilic granuloma of the skull. Neurosurgery 1984;15:155-61.

5 Miura AB. Hand-Schüller-Christian disease, eosinophilic granuloma. Nippon Rinsho 1993;51:1102-6. (In Japanese.)

6 The writing group of the histiocyte society. Histiocytosis syndromes in children. Lancet 1987;i:208-9.

7 Gavrieli Y, Sherman Y, Ben-Sasson SA. Identification of programmed cell death in situ via specific labeling of programmed cell death in situ via specific labeling of
nuclear DNA fragmentation. $\mathcal{f}$ Cell Biol 1992;119:493501 .

8 Mundle S, Iftikhar A, Shetty V, Dameron S, WrightQuinones V, Marcus B, et al. Novel in situ double labeling for simultaneous detection of proliferation and apoptosis. F Histochem Cytochem 1994;42:1533-7.

9 Ohta M, Iwaki T, Kitamoto T, Takeshita I, Tatesishi J, Fukui M. MIB-1 staining index and scoring of histologic features in meningioma. Cancer 1994;74:3176-89.

10 Gorczyca W, Gong J, Darzynkiewicz Z. Detection of DNA strand breaks in individual apoptotic cells by the in situ terminal deoxynucleotidyl transferase and nick translation terminal deoxynucleotidyl transferase

11 Kasagi N, Gomyo Y, Shirai H, Tsujitani S, Ito H. Apoptotic cell death in human gastric carcinoma: analysis by terminal deoxynucleotidyl transferase-mediated dUTP-biotin nick end labeling. Ipn ₹ Cancer Res 1994;85:939-45.

12 Roca-Miralles M, Kanitakis J, Be'jui-Thivolet F, Schmitt $D$, Castels-Rondellas A, Thivolet J. Expression of neuronspecific enolase immunoactivity by cutaneous and extracutaneous Langerhans-cell histiocytoses ("X"). $\mathcal{F}$ Dermatol 1992;19:947-52.

13 Yu RC, Chu C, Buluwela L, Chu AC. Clonal proliferation of Langerhans cells in Langerhans cell histiocytosis. Lancet 1994;343:767-8.

14 Burger PC, Scheithauer BW, Vogel FS. Surgical pathology of the nervous system and its coverings. New York: Churchill Livingstone, 1991:6-10.

15 Kerr JFR, Wyllie AH, Currie AR. Apoptosis: a basic biological phenomenon with wide-ranging implications in tissue kinetics. Br f Cancer 1972;26:239-57.

16 Williams GT. Programmed cell death: apoptosis and oncogenesis. Cell 1991;65:1097-8.

17 Reed JC. Mini-Review: cellular mechanisms of disease series, bcl-2 and the regulation of programmed cell death. f Cell Biol 1994;124:1-6.

18 Willman CL, Busque L, Griffith BB, Favara BE, McClain $\mathrm{KL}$, Duncan MH, et al. Langerhans'-cell histiocytosis (histiocytosis X)-a clonal proliferative disease. $N$ Engl $\mathcal{F}$ Med 1994;331:154-60.

19 Carson DA, Ribeiro JM. Apoptosis and disease. Lancet 1993;341:1251-4.

20 Cohen M, Zornoza J, Cangir A, Murray JA, Wallace S. Direct injection of methylprednisolone sodium succinate in the treatment of solitary eosinophilic granuloma of bone. Radiology 1980;136:289-93.

21 Eitan S, Schwartz M. A transglutaminase that converts interleukin-2 into a factor cytotoxic to oligodendrocytes. Science 1993;261:106-8. 